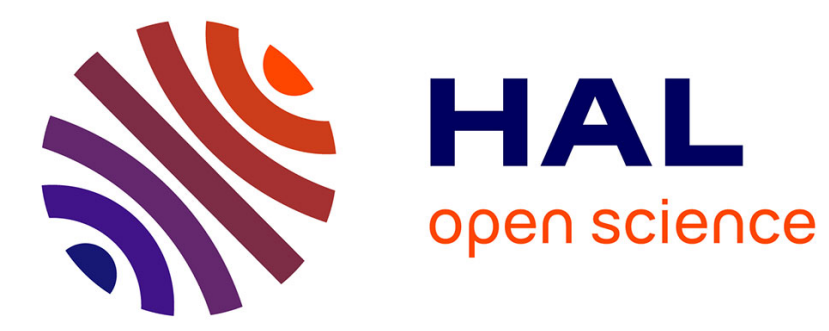

\title{
Hyperphagia in short bowel patients: Fat-free mass is a strong predictor
}

Cécile Bétry, Madeleine Lauverjat, Thomas Mouillot, Charlotte Bergoin, Didier Barnoud, Sabrina Ait, Cécile Chambrier

\section{To cite this version:}

Cécile Bétry, Madeleine Lauverjat, Thomas Mouillot, Charlotte Bergoin, Didier Barnoud, et al.. Hyperphagia in short bowel patients: Fat-free mass is a strong predictor. Nutrition, 2019, 62, pp.146 151. 10.1016/j.nut.2018.12.013 . hal-03486144

\section{HAL Id: hal-03486144 \\ https://hal.science/hal-03486144}

Submitted on 20 Dec 2021

HAL is a multi-disciplinary open access archive for the deposit and dissemination of scientific research documents, whether they are published or not. The documents may come from teaching and research institutions in France or abroad, or from public or private research centers.
L'archive ouverte pluridisciplinaire HAL, est destinée au dépôt et à la diffusion de documents scientifiques de niveau recherche, publiés ou non, émanant des établissements d'enseignement et de recherche français ou étrangers, des laboratoires publics ou privés.

\section{다)(1) $(5$}

Distributed under a Creative Commons Attribution - NonCommerciall 4.0 International 
1 Hyperphagia in short bowel patients: fat-free mass is a strong predictor

2

3 Cécile Bétry $^{1,2}, \mathrm{MD}-\mathrm{PhD}$, Madeleine Lauverjat ${ }^{2}, \mathrm{MD}$, Thomas Mouillot ${ }^{2,3}$, MD, Charlotte

4 Bergoin $^{2}, \mathrm{MD}$, Didier Barnoud ${ }^{2}, \mathrm{MD}$, Sabrina $\mathrm{Ait}^{2}, \mathrm{MD}$, Cécile Chambrier ${ }^{2}, \mathrm{MD}-\mathrm{PhD}$

$5{ }^{1}$ The Medical School, University of Nottingham, Nottingham, UK

$6 \quad{ }^{2}$ Unité de nutrition clinique intensive, Hospices Civils de Lyon, Lyon, France

$7 \quad{ }^{3}$ CHU François Mitterrand, Bourgogne-Franche Comté, Dijon, France

$9{ }^{*}$ Corresponding author (present address):

10 Cécile Bétry, M.D., Ph.D.

11 CHU Grenoble Alpes, Diabétologie

$12 \quad$ CS10217

1338043 Grenoble Cedex 9

14 France

15 cbetry@chu-grenoble.fr

16

17 Acknowledgments

18 We thank the staff of the Nutrition Intensive Care Unit for their helpful assistance in the data

19 collection. We thank Peter Tucker for proofreading this manuscript.

21 C. Bétry, T. Mouillot and C. Chambrier contributed to the conception and design of the

22 research; C. Bétry, M. Lauverjat, C. Bergoin, D. Barnoud, S. Ait and C. Chambrier

23 contributed to the acquisition of the data; C. Bétry and C. Chambrier contributed to the

24 analysis and the interpretation of the data. C. Bétry drafted the manuscript. All authors 
25 critically revised the manuscript, agree to be fully accountable for ensuring the integrity and

26 accuracy of the work, and read and approved the final manuscript

27

\section{Funding source}

29 C. Bétry was funded by the FRM during the writing of this article (Grant 40184). This

30 research did not receive any other grant from funding agencies in the public, commercial, or

31 not-for-profit sectors. The funding bodies did not have any involvement in the design/conduct

32 of the research, in data analysis/interpretation, or in writing/approval of the manuscript.

33

34 Declarations of interest: none 


\section{Title}

2 Hyperphagia in short bowel patients: fat-free mass is a strong predictor

3

$4 \underline{\text { Abstract }}$

5 Background: Some short bowel syndrome patients develop hyperphagic behaviour. Such an

6 increase in food intake stimulates intestinal adaptation and limits dependence on parenteral

7 nutrition. The aim of this study was to determine the factors modulating food consumption in

8 short bowel syndrome patients.

9 Methods: The associations between oral energy intake and anthropometric, metabolic,

10 nutritional, and intestinal absorption-related characteristics were determined in a monocentric

11 cohort of short bowel syndrome patients on parenteral nutrition with a stable nutritional

12 status. Body composition was assessed by dual X-ray absorptiometry. Data were

13 retrospectively collected from clinical records.

14 Results: After screening, 38 adult patients with a short bowel syndrome under parenteral

15 nutrition and without intestinal transplantation or debilitating gastrointestinal symptems were

16 included in this study. Oral energy intake ranged from 577 to $4054 \mathrm{kcal}$ per day. Oral energy

17 intake correlated positively with weight, fat-free mass, hand-strength, resting energy

18 expenditure and negatively with free triiodothyronine and C-reactive protein using Spearman

19 correlation. Fat-free mass and thyroid-stimulating hormone remained positively correlated

20 with oral energy intake independently of all other parameters in a multilinear regression

21 model.

22 Conclusions: Fat-free mass is a strong predictor of oral energy intake in short bowel

23 syndrome patients under parenteral nutrition and without debilitating gastrointestinal

24 symptoms. Increasing fat-free mass using a physical activity program could be a way to

BMI, body mass index, CRP, C-reactive protein, DEXA, dual X-ray absorptiometry, FFM, fat-free mass, FFMI, fat-free mass index, FM, fat mass, FMI, fat mass index, FT3, free triiodothyronine, FT4, free thyroxine, REE, resting energy expenditure, TSH, thyroidstimulating hormone 
25 stimulate oral energy intake in short bowel syndrome patients. This assumption should be 26 assessed by further studies.

27

28 Keywords: parenteral nutrition; energy metabolism; body composition; fat-free mass;

29 thyrotropin; intestinal absorption 


\section{Introduction}

In adults, short bowel syndrome is secondary to intestinal resection for gastrointestinal conditions including mesenteric ischemia, inflammatory bowel diseases, occlusive syndromes or bowel cancers. This syndrome is defined by a remnant bowel length inferior to $150-200$ $\mathrm{cm}$. Massive small intestine resection induces temporary or permanent intestinal failure owing to malabsorption related to a reduced intestinal surface ${ }^{1}$.

The development of parenteral nutrition during the last decades has changed the prognosis of short bowel syndrome patients. However, long-term parenteral nutrition induces serious complications, e.g., central venous catheter-related bloodstream infections and intestinal failure-associated liver disease ${ }^{2,3}$. Moreover, home parenteral nutrition is an expensive treatment associated with a poor quality of life ${ }^{4,5}$. Thus, one of the main objectives of short bowel syndrome patient care is to promote intestinal adaptation and to reduce dependence on parenteral nutrition. Some short bowel syndrome patients present adaptive hyperphagia which is critical for intestinal adaptation ${ }^{6,7}$. Stimulating food consumption could therefore be a safe and inexpensive way to reduce dependence on parenteral nutrition ${ }^{8}$.

Few studies have assessed the factors which modulate oral energy intake in short bowel syndrome patients. These studies focused on the links between hyperphagia and certain hormones - namely leptin, dipeptidyl peptidase-4, peptide YY and ghrelin, with inconclusive results ${ }^{9-11}$. Since fat-free mass correlates with oral energy intake in healthy normal weight and obese subjects, we hypothesised that body composition could at least partly determine oral energy intake in short bowel syndrome patients ${ }^{12-14}$. The aim of our study was to determine the factors associated with oral energy intake in short bowel syndrome patients on home parenteral nutrition and stable nutritional status. 


\section{Materials and Methods}

\section{$54 \quad$ Study population}

55

56

This study was based on observational routinely-collected data from one home parenteral nutrition referral centre in Lyon, France. Health data were recorded in computerised patient records during clinical practice. In our centre, every patient, who is under home parenteral nutrition for extended period, is routinely hospitalised for nutritional assessment. All short bowel subjects, who were hospitalised for this assessment ind from January 2007 to October 2016 were screened. Clinically stable patients with a short bowel syndrome for at least 1 year and on home parenteral nutrition were included. Short bowel syndrome was defined as a remnant short bowel length inferior to $200 \mathrm{~cm}$ with or without colon resection ${ }^{1}$. Owing to the eating difficulties of adult patients with a paediatric short bowel syndrome, these patients were excluded from our study ${ }^{15}$. Patients with intestinal transplantation, and those with an oral energy intake below $500 \mathrm{kcal}$ and/or frequent nausea/vomiting were also excluded.

\section{Nutritional assessment}

All included patients received a standardised nutritional assessment during a hospital stay of a few days. If a patient received several nutritional assessments, only the data from the most recent hospitalisation were collected. These nutritional assessments are routinely performed in the home parenteral nutrition referral centre of Lyon. The purpose is to ensure that the long-term home parenteral nutrition is appropriate. Nutritional assessment includes body composition analysis and anthropometry, a 3-day food diary, indirect calorimetry, blood and stool tests.

\section{Body composition and anthropometry}


All anthropometric measurements were performed by medical practitioners. Weight, height, brachial circumference at the centre of the upper limb and triceps skinfold at the same site using an anthropometric calliper were determined. The device used for determination of handgrip strength changed in 2012. Thus, only handgrip strength measured with a Jamar dynamometer data after 2012 was considered. Fat-free mass and fat mass were estimated by dual X-ray absorptiometry (DEXA). Indirect calorimetry (Quark RMR - Cosmed) was performed for $30 \mathrm{~min}$ in fasting subjects after discontinuation of parenteral nutrition for at 83 least six hours.

\section{Determination of food intake and definition of hyperphagia} out at home prior to hospitalisation.

Some authors have attempted to define hyperphagia in short bowel syndrome but no clear definition has yet to emerge. Based on a review of the literature, two principal definitions have been retained in this paper in order to classify the subjects as hyperphagic or non-hyperphagic. We defined subjects as hyperphagic if they had an oral energy intake

91 greater than either $40 \mathrm{kcal} \cdot \mathrm{kg}^{-1} \cdot \mathrm{day}^{-1} 9$ or one and a half times their resting energy expenditure 926.

\section{Blood and stool tests} protein (CRP) level, thyroid function, and plasma amino acids in order to measure plasma citrulline concentration. Intestinal carbohydrate absorption was determined using a blood D-

97 xylose test. Fasting subjects were given $5 \mathrm{~g}$ of D-xylose dissolved in $200 \mathrm{~mL}$ water and D-

98 xylose blood concentration was measured after one hour. Stools were collected by subjects for 99 three days at home before hospitalisation in order to determine average daily stool weight. 


\section{Ethics statement}

According to current French law, patients were individually informed that their data

102 could be used for research (MR-003 reference methodology) and did not object. Data were

103 collected during routine medical examination. Patients did not undergo any treatment or

104 examination specifically devised to collect data for this study.

\section{Statistical analysis}

106 Statistical analysis was performed using RStudio Version 1.0.136 with occasional

107 reliance on 'prettyR', 'RVAideMemoire', 'ggplot2', 'car', 'zoo' ${ }^{16}$. Owing to the small

108 number of patients, non-parametric statistics were used. Data are presented as median and

$10995 \%$ confidence interval. All P-values below 0.05 were considered significant.

110 The relationship between oral energy intake and the following 24 variables were

111 examined: age, sex, short bowel syndrome causes, bowel anatomy, remnant small bowel

112 length, duration of short bowel syndrome, resting energy expenditure, body weight, fat-free

113 mass, fat mass, brachial circumference, skinfold, hand strength, plasma albumin, thyroid-

114 stimulating hormone (TSH), free triiodothyronine (FT3), free thyroxine (FT4), CRP,

115 parenteral energy intake, number of parenteral infusions per week, volume of parenteral

116 infusion stool weight, one-hour D-xylose blood concentration and citrullinemia. In order to

117 determine the predictive factors of oral energy intake, a univariate analysis was first

118 completed using Spearman correlations and Wilcoxon-Mann-Whitney test or Kruskal-Walis

119 test for categorical variables with more than two factors. For the Spearman correlation

120 determination, the results were expressed as Rho and 95\% confidence interval. Confidence

121 intervals were determined using a bootstrap with 1000 replicates.

122 Subsequently, a multiple regression analysis was performed to determine the factors

123 significantly and independently associated with oral energy intake. Variables with P-value 
124 below 0.1 in univariate analyses as well as age and sex were entered. Hand-strength was 125 excluded because too many values were missing. Owing to the collinearity between weight 126 and fat-free mass, assessed by variance influence factor, weight was replaced by fat mass.

127 Variance influence factor was below 5 for each factor after this adjustment. The residual of 128 multiple linear regression was normally distributed using the Shapiro-Wilk test ${ }^{17}$. 
$129 \underline{\text { Results }}$

$130 \quad$ Patient inclusion

131 All patients $(\mathrm{n}=119)$ on home parenteral nutrition and hospitalised for a nutritional

132 assessment between January 2007 and October 2016 were screened (Figure 1). A total of 38

133 patients were included. 


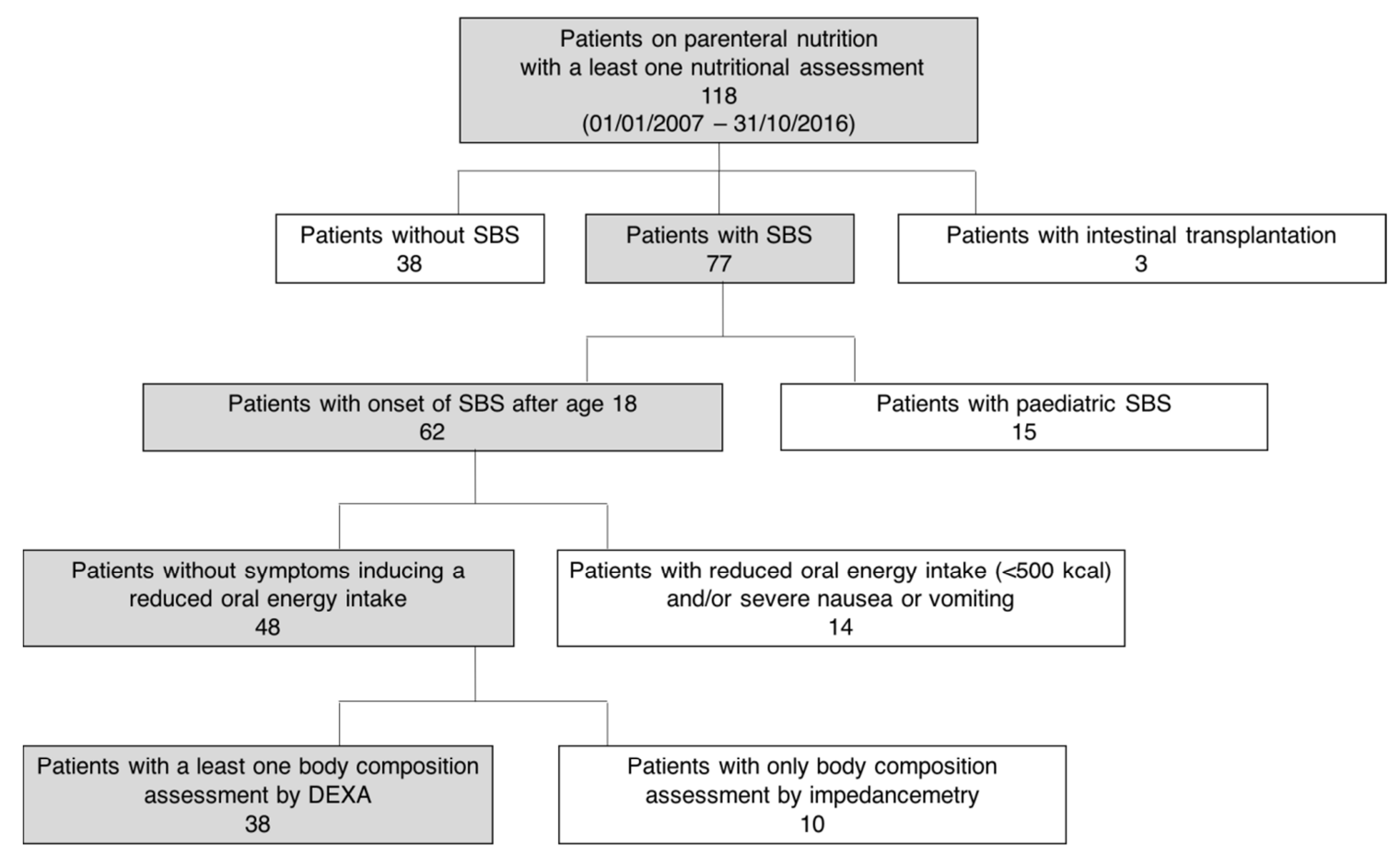

135 Figure 1. Patient inclusion flowchart.

136 SBS, short bowel syndrome, DEXA, Dual-energy X-ray absorptiometry 


\section{Patient characteristics}

138 The study population was made up of 24 males (63\%) and 14 females with a median 139 age of 63 years [IC95\%: 37-77]. Patients underwent intestinal resection due to mesenteric

140 ischaemia $(n=24,63 \%)$, small bowel obstruction $(n=5,13 \%)$, intestinal tumour $(n=3,8 \%)$,

141 radiation enteritis $(n=3,8 \%)$, or other causes $(n=3,8 \%)$. The median remnant small bowel

142 length was $70 \mathrm{~cm}$ [IC95\%: 8-164]. Among the 18 patients with a stoma, 16 patients had an

143 end-jejunostomy while 2 had a colostomy with a jejuno-colic anastomosis. Among the 20

144 patients without a stoma, 17 had a jejuno-colic anastomosis and 3 a jejuno-ileal anastomosis.

145 The median period between nutritional assessment and bowel resection was 52 months

146 [IC95\%: 16-214]. Table 1 shows the demographic, anthropometric, metabolic, nutritional and 147 intestinal absorption-related characteristics. 


\begin{tabular}{|c|c|}
\hline & Median [IC 95\%] \\
\hline age, years, $n=38$ & $63[37,77]$ \\
\hline sex, $\%,(\mathrm{M} / \mathrm{F}), \mathrm{n}=38$ & $63 \%(24 / 14)$ \\
\hline \multicolumn{2}{|l|}{ Anthropometric characteristics } \\
\hline body weight, $\mathrm{kg}, \mathrm{n}=38$ & $63.0[48.9,80.0]$ \\
\hline BMI, kg.m-2, $\mathrm{n}=38$ & $22.0[17.3,26.8]$ \\
\hline FFM, $\mathrm{kg}, \mathrm{n}=38$ & $42.9[34.9,58.2]$ \\
\hline FFMI, kg.m-2, $\mathrm{n}=38$ & $15.5[13.4,19.5]$ \\
\hline $\mathrm{FM}, \mathrm{kg}, \mathrm{n}=38$ & $16.5[7.9,28.3]$ \\
\hline FMI, kg.m-2, $\mathrm{n}=38$ & $6.2[2.7,11.0]$ \\
\hline brachial circumference, $\mathrm{cm}, \mathrm{n}=35$ & $27[23,34]$ \\
\hline skinfold, $\mathrm{mm}, \mathrm{n}=35$ & $14[5,33]$ \\
\hline Hand strength, $\mathrm{kg}, \mathrm{n}=14$ & $32[17,43]$ \\
\hline \multicolumn{2}{|l|}{ Metabolic characteristics } \\
\hline REE, kcal, $n=37$ & $1394[1053,1685]$ \\
\hline $\mathrm{TSH}, \mathrm{mUI} / \mathrm{L}, \mathrm{n}=36$ & $1.29[0.48,3.07]$ \\
\hline FT3, pmol/L, $\mathrm{n}=35$ & $4.1[3.3,5.2]$ \\
\hline FT4, pmol/L, $\mathrm{n}=35$ & $12.8[10.1,17.3]$ \\
\hline $\mathrm{CRP}, \mathrm{mg} / \mathrm{L}, \mathrm{n}=38$ & $3.3[0.9,15.7]$ \\
\hline albumin, $g / L, n=38$ & $37.3[28.1,44.0]$ \\
\hline \multicolumn{2}{|l|}{ Nutritional characteristics } \\
\hline oral energy intake, $\mathrm{kcal} / \mathrm{d}, \mathrm{n}=38$ & $2087[1293,3586]$ \\
\hline parenteral energy intake, $\mathrm{kcal} / \mathrm{d}, \mathrm{n}=38$ & $840[286,1682]$ \\
\hline number of parenteral infusions, per week, $\mathrm{n}=38$ & $4[2,7]$ \\
\hline volume of parenteral infusion, $\mathrm{L}$, per bag, $\mathrm{n}=38$ & $1142[286,3038]$ \\
\hline $\begin{array}{l}\text { amino acid content of parenteral infusion, } \mathrm{g} / \mathrm{kg} / \mathrm{day} \text {, per bag, } \\
\mathrm{n}=38\end{array}$ & $0.62[0.24,1.22] \mathrm{g} / \mathrm{kg} / \mathrm{day}$ \\
\hline \multicolumn{2}{|l|}{ Intestinal absorption-related characteristics } \\
\hline stool weight, g per day, $\mathrm{n}=35$ & $1165[186,2939]$ \\
\hline one-hour D-xylose blood concentration, $\mathrm{mmol} / \mathrm{L}, \mathrm{n}=31$ & $0.60[0.24,1.51]$ \\
\hline citrullinemia, $\mathrm{mmol} / \mathrm{L}, \mathrm{n}=38$ & $20[7,43]$ \\
\hline
\end{tabular}

148 Table 1. Anthropometric, metabolic, nutritional and intestinal absorption-related

149 characteristics of the population. 
150 BMI, body mass index, FFM, fat-free mass, FFMI, fat-free mass index, FM, fat mass, FMI,

151 fat mass index REE, resting energy expenditure, TSH, thyroid-stimulating hormone, FT3, free

152 triiodothyronine, FT4, free thyroxine, CRP, C-reactive protein 


\section{Oral and parenteral energy intake}

154 Patients were assigned either to the hyperphagic or the non-hyperphagic group 155 according to the two retained hyperphagia definitions, namely an oral energy intake greater

156 than $40 \mathrm{kcal}^{\mathrm{kg}}{ }^{-1}$. day ${ }^{-1}$ (Figure 2A) or one and a half times their resting energy expenditure

157 (Figure 2B). Subjects with hyperphagia accounted for $26 \%(n=10)$ using the first definition 158 (Figure 2A) and 43\% (n=16) using the second definition (Figure 2B). As illustrated in Figures

$1592 \mathrm{~A}$ and $2 \mathrm{~B}$, oral energy intake had a Gaussian distribution which did not make it possible to 160 clearly distinguish the group of hyperphagic patients from the group of non-hyperphagic 161 patients. Whatever the definition of hyperphagia, the hyperphagic patients were only the 162 patients with the greatest energy intake (on the right of the curve). Given this and for further 163 analyses, the population was analysed as a whole. Oral and parenteral energy intake and 164 resting energy expenditure for each patient are given in Figure 2C. In the vast majority of 165 cases, oral energy intake provided more than resting energy needs. 
A

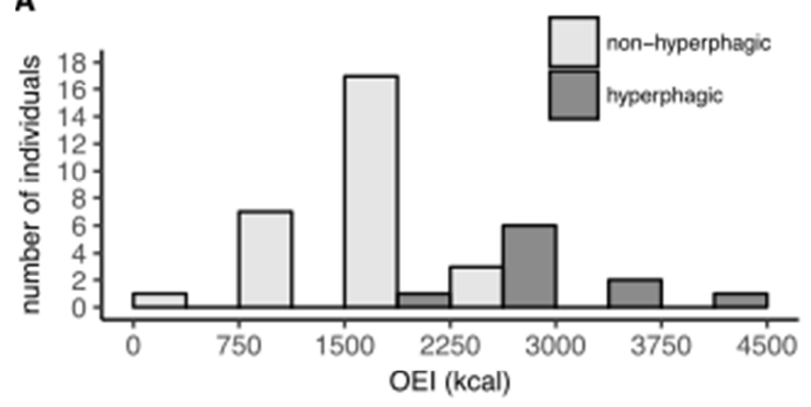

C

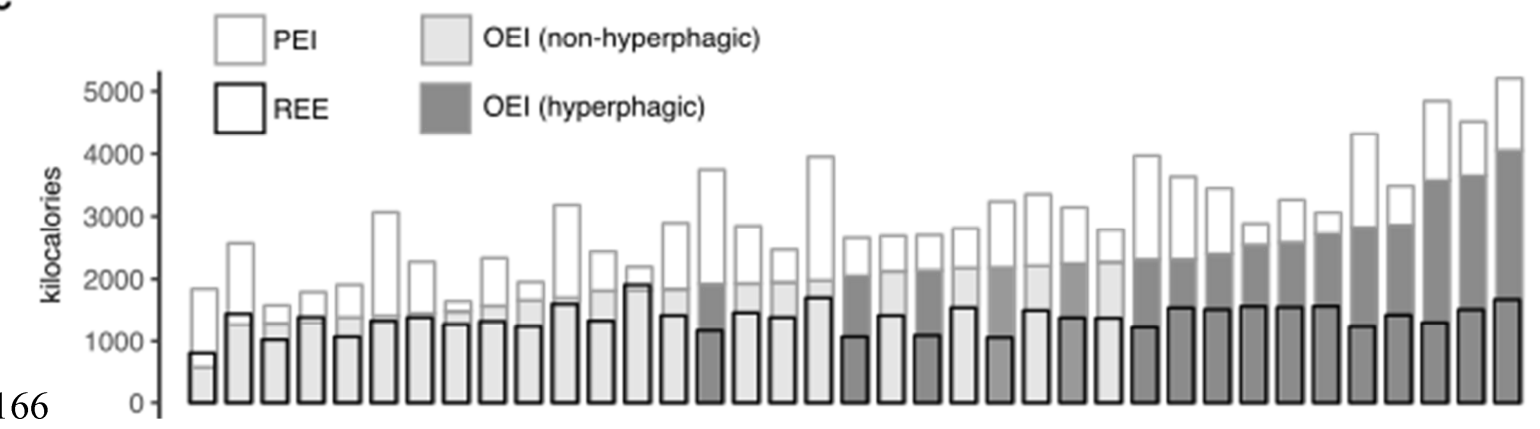

167 Figure 2. Oral energy intake (OEI), parenteral energy intake (PEI) and resting energy

168 expenditure (REE) in the cohort of 38 short bowel syndrome patients

169 A. Distribution of the OEI in patients designated either non-hyperphagic (OEI/weight $<40$

$170 \mathrm{kcal} . \mathrm{kg}$-1.day-1, $\mathrm{n}=28,73.7 \%$ ) or hyperphagic patients (OEI/weight $\geq 40 \mathrm{kcal} . \mathrm{kg}-1$.day-1,

$171 \mathrm{n}=10,26.3 \%)$

172 B. Distribution of the OEI in patients designated either non-hyperphagic (OEI $<1.5 *$ REE,

$173 \mathrm{n}=21,56.8 \%)$ or hyperphagic patients (OEI $\geq 1.5 *$ REE, $\mathrm{n}=16,43.2 \%)$

174 C. Individual variations of parenteral energy intake (PEI), oral energy intake (OEI) and

175 resting energy expenditure (REE). The subjects were ranked according to their oral energy

176 intake. OEI is marked in dark grey if patients are hyperphagic with either of the two

177 definitions.

178 One subject was not represented in Figure 2B and 2C because the REE was missing. 


\section{Relationship between oral energy intake and characteristics of the population and}

\section{0 parenteral intake}

181 Significant univariate analyses are illustrated in Figure 3. Oral energy intake was 182 correlated with weight $(\mathrm{Rho}=0.418[0.095,0.684], \mathrm{P}=0.009)$, fat-free mass $(\mathrm{Rho}=0.474$

$183[0.158,0.699], \mathrm{P}=0.003)$ but not with fat mass $($ Rho $=0.021[-0.313,0.337, \mathrm{P}=0.90)$.

184 Despite the low numbers of subjects with a measure of hand strength $(n=14)$, oral energy 185 intake was significantly correlated with hand strength (Rho $=0.585[0.053,0.869])$. Oral 186 energy intake was also positively correlated with resting energy expenditure (Rho $=0.365$ $187[0.042,0.628], \mathrm{P}=0.03)$ and negatively correlated with FT3 (Rho $=-0.346[-0.622,-0.031]$, $188 \mathrm{P}=0.04$ ) and CRP (Rho $=-0.360[-0.625,-0.027]$ (Figure 3). Oral energy intake was not 189 correlated with any other parameters including age, mean remnant small bowel length, short 190 bowel syndrome duration, parameters related to parenteral nutrition and intestinal functions

191 (Table 2). The oral energy intake in subgroups of patients categorised by sex, short bowel 192 syndrome causes and bowel anatomy was not significantly different $(\mathrm{P}=0.11, \mathrm{P}=0.97$, $193 \mathrm{P}=0.88$ respectively). Using multiple linear regression analysis with oral energy intake as the 194 dependent variable, and with age, sex, fat-free mass, resting energy expenditure, TSH, FT3 195 and CRP as independent variables, oral energy intake positively correlated with fat-free mass $196(\mathrm{P}<0.05)$ and TSH $(\mathrm{P}<0.01)$ independently of all other parameters (Table 3$).$ 

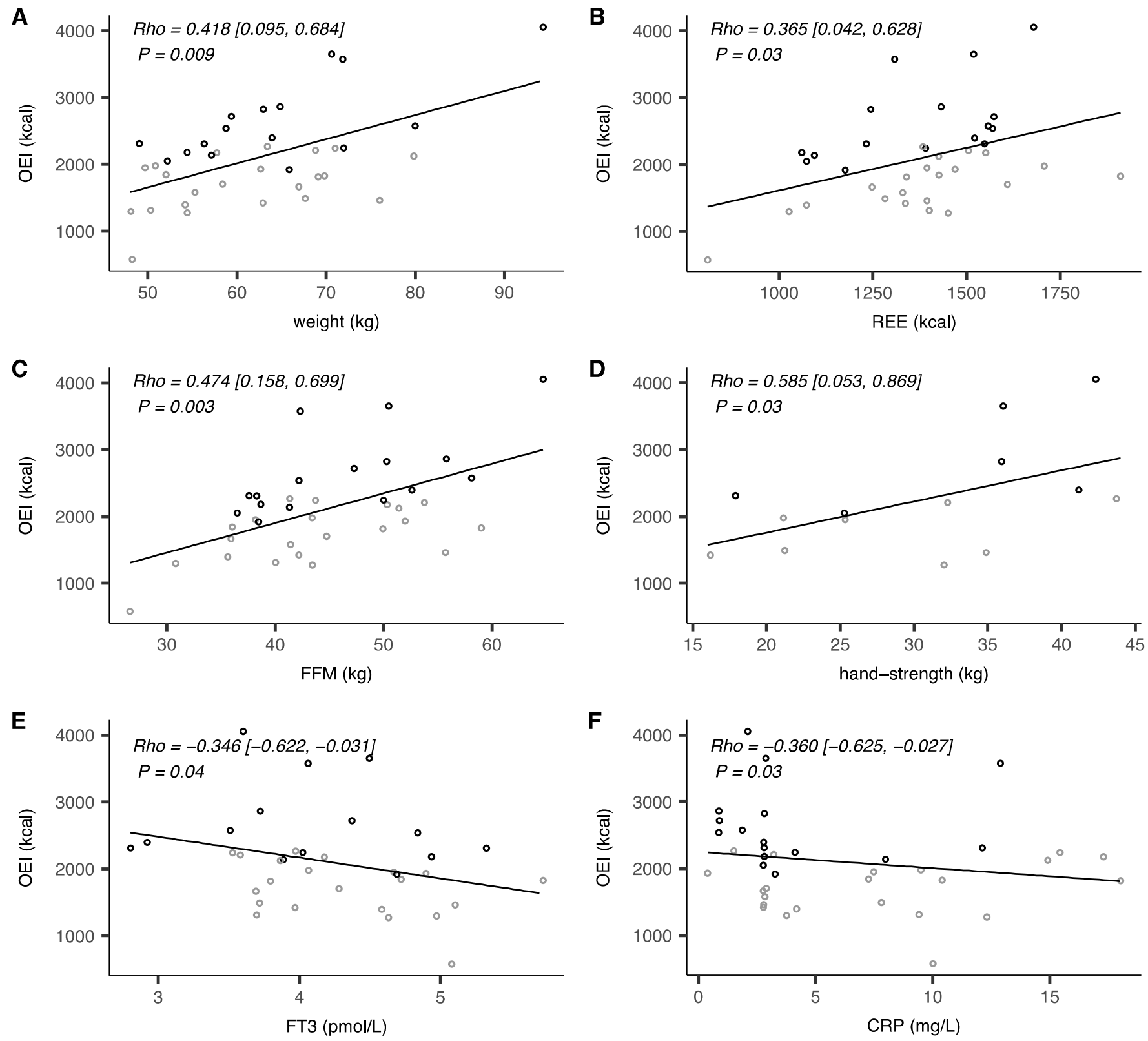

イフ

198 Figure 3. Significant associations between oral energy intake (OEI) and body weight, resting

199 energy expenditure (REE), fat-free mass (FFM), hand strength, free triiodothyronine (FT3),

200 and C-reactive protein (CRP).

201 Univariate associations were assessed using Spearman correlations. The confidence interval

202 of the Spearman correlation coefficients was determined using a bootstrap with 1000

203 replicates. 
204 Hyperphagic patients with either of the two definitions are marked in dark grey and non205 hyperphagic patients are marked in light grey. 


\begin{tabular}{|l|l|l|l|}
\hline & Rho & IC95 & p \\
\hline age, years & -0.051 & {$[-0.385,0.288]$} & 0.76 \\
\hline FM, kg & 0.021 & {$[-0.313,0.337]$} & 0.90 \\
\hline brachial circumference, cm & 0.065 & {$[-0.322,0.401]$} & 0.71 \\
\hline skinfold, mm & -0.169 & {$[-0.511,0.213]$} & 0.33 \\
\hline TSH, mUI/L & 0.322 & {$[-0.002,0.621]$} & 0.06 \\
\hline FT4, pmol/L & -0.204 & {$[-0.503,0.146]$} & 0.24 \\
\hline parenteral energy intake, kcal/d & 0.154 & {$[-0.175,0.486]$} & 0.36 \\
\hline number of parenteral infusions, per week & 0.098 & {$[-0.263,0.421]$} & 0.56 \\
\hline volume of parenteral infusion, L, per bag & 0.129 & {$[-0.217,0.448]$} & 0.44 \\
\hline albumin, g/L & 0.144 & {$[-0.213,0.475]$} & 0.39 \\
\hline duration of the short bowel syndrome, months & -0.022 & {$[-0.367,0.317]$} & 0.90 \\
\hline remnant small bowel length, cm & -0.010 & {$[-0.366,0.344]$} & 0.95 \\
\hline stool weight, g & 0.050 & {$[-0.340,0.395]$} & 0.77 \\
\hline one-hour blood D-xylose concentration, mmol/L & 0.112 & {$[-0.246,0.434]$} & 0.55 \\
\hline citrullinemia, mmol/L, $\mathrm{n}=38$ & 0.094 & {$[-0.220,0.408]$} & 0.57 \\
\hline
\end{tabular}

207 Table 2. Correlation between oral energy intake and anthropometric, metabolic, nutritional

208 and absorption parameters using Spearman's rank correlation

209 IC 95\% was determined after bootstrap with 1000 replicates.

210 FM, fat mass, TSH, thyroid-stimulating hormone, FT4, free thyroxine 


\begin{tabular}{|l|l|l|l|}
\hline Predictor variables & $\beta$ (Standardised coefficients) & Standard error & P-value \\
\hline sex & -0.206 & 0.14 & 0.30 \\
age & 0.103 & 0.17 & 0.44 \\
FFM & 0.660 & 0.44 & $<0.01$ \\
FM & 0.187 & 0.11 & 0.18 \\
REE & 0.307 & 0.40 & 0.12 \\
TSH & 0.398 & 0.05 & $<0.01$ \\
FT3 & -0.044 & 0.29 & 0.74 \\
CRP & -0.054 & 0.05 & 0.68 \\
\hline
\end{tabular}

211 Table 3. Multivariate model with oral energy intake as the dependent variable and predictor

212 variables as the independent variables.

213 FFM, fat-free mass, FM, fat mass, REE, resting energy expenditure, TSH, thyroid-stimulating

214 hormone, FT3, free triiodothyronine 
In short bowel syndrome patients, the development of hyperphagia is essential for

intestinal adaptation and subsequently to reduce dependence on parenteral nutrition. In short

bowel syndrome patients, luminal nutrients are essential for intestinal adaptation and

interest in this area, previous studies have failed to determine the factors that explain the increase in food consumption in some short bowel syndrome patients.

In this observational study, we reported the correlations between oral energy intake and the factors potentially involved in oral energy intake in these patients. The most striking result is that oral energy intake strongly correlated with fat-free mass, both in linear and multiple linear regression models. We hypothesise that fat-free mass drives oral energy intake in short bowel syndrome patients. However, one may argue that in short bowel syndrome patients, greater oral energy intake induces a better nutritional status leading to greater fat-free mass. This hypothesis is unlikely since the correlation between fat-free mass and oral energy intake is shared across many different populations, i.e. healthy normal weight, overweight or

230 obese adults and adolescents who are not expected to be malnourished ${ }^{12-14,18-20}$. Furthermore,

231 all of the patients in our cohort were thoroughly monitored before their nutritional assessment 232 and the parenteral nutrition was periodically adjusted to maintain a satisfactory nutritional status. A difference in nutritional status within the cohort was therefore not expected. We also

234 found a positive correlation between TSH and oral energy intake in the multivariate model.

235 One possible explanation for this result is that the subjects with the highest oral energy intake

236 tend to be overfed. Indeed, an increase in TSH was previously demonstrated in response to 237 experimental overfeeding ${ }^{21}$.

238 In order to understand the drivers of oral energy intake, one important and 239 controversial issue was to know if parenteral nutrition inhibits oral intake. In our study, oral 
energy intake was not correlated with any parameter related to parenteral nutrition, namely

241 energy, number and volume of infusions in good agreement with other observational studies

$242{ }^{6,22}$. It is also reinforced by experimental studies showing the lack of acute effect of parenteral 243 nutrition on hunger and satiety both in short bowel syndrome patients ${ }^{23}$ and healthy subjects

$244{ }^{24}$ even if some other studies suggest an effect of parenteral nutrition on subsequent oral 245 energy intake ${ }^{25,26}$. Our results also showed that the duration of short bowel syndrome is not 246 associated with oral energy intake at least in the included patients, which are on parental 247 nutrition for at least one year.

248 The main limitation of our study is its retrospective design. This limitation is related to 249 the difficulty of collecting prospective data in short bowel syndrome patients owing to the low 250 population size. To limit the bias of recruitment and ensure consecutive recruitment during 251 the study period, we screened all patients with a nutritional assessment in our unit. We 252 analysed only fat-free mass data assessed by DEXA to ensure the homogeneity of the results. 253 Oral energy intake determination was based on a 3-day diary and one concern is therefore 254 possible misreporting of oral energy intake. Nevertheless, good agreement between objective 255 and subjective assessment of oral energy intake in the short bowel syndrome population has 256 been previously shown ${ }^{7}$. Finally, we excluded patients with limited oral energy intake and/or 257 frequent nausea/vomiting. In our retrospective study, these gastrointestinal symptoms were 258 not precisely quantified. Thus, we were not able to include them in statistical analyses and to 259 determinate in which measure they affect oral energy intake.

260 This study has revealed that fat-free mass is an important determinant of oral energy 261 intake. One way to increase fat-free mass could be to increase physical activity. Such a 262 strategy was previously assessed with a resistance training program inducing an increase in 263 both fat-free mass and energy intake in nine short bowel patients ${ }^{27}$. This study is promising 
264 and should be validated in a larger cohort. Future work should also assess, if increasing fat265 free mass limits dependence on parenteral nutrition

266 In conclusion, our work suggests that fat-free mass is an important determinant of oral 267 energy intake in short bowel syndrome patients under parenteral nutrition and without 268 debilitating digestive symptoms. This finding adds to a body of evidence highlighting the 269 correlation of fat-free mass and oral energy intake in other populations. Future studies are 270 therefore required to elucidate the links between oral energy intake, fat-free mass, physical 271 activity and dependence on parenteral nutrition in short bowel syndrome patients. It could 272 help to better follow up these patients in order to ensure both intestinal adaptation and 273 nutritional adequacy. 
275 1. Pironi L, Arends J, Baxter J, et al. ESPEN endorsed recommendations. Definition and classification of intestinal failure in adults. Clin Nutr. 2015;34(2):171-180.

277 doi:10.1016/j.clnu.2014.08.017.

278

279

280

281

282

283

284
2. Dibb M, Soop M, Teubner A, et al. Survival and nutritional dependence on home parenteral nutrition: Three decades of experience from a single referral centre. Clin Nutr Edinb Scotl. 2017;36(2):570-576. doi:10.1016/j.clnu.2016.01.028.

3. Santarpia L, Buonomo A, Pagano MC, et al. Central venous catheter related bloodstream infections in adult patients on home parenteral nutrition: Prevalence, predictive factors, therapeutic outcome. Clin Nutr Edinb Scotl. 2016;35(6):1394-1398. doi:10.1016/j.clnu.2016.03.009.

4. Berghöfer P, Fragkos KC, Baxter JP, et al. Development and validation of the diseasespecific Short Bowel Syndrome-Quality of Life (SBS-QoL ${ }^{\mathrm{TM}}$ ) scale. Clin Nutr Edinb Scotl. 2013;32(5):789-796. doi:10.1016/j.clnu.2012.12.001.

5. Roskott AM, Groen H, Rings EHHM, et al. Cost-effectiveness of intestinal transplantation for adult patients with intestinal failure: a simulation study. Am J Clin Nutr. 2015;101(1):79-86. doi:10.3945/ajcn.114.083303.

6. Crenn P, Morin MC, Joly F, Penven S, Thuillier F, Messing B. Net digestive absorption and adaptive hyperphagia in adult short bowel patients. Gut. 2004;53(9):1279-1286. doi:10.1136/gut.2003.030601.

7. Messing B, Pigot F, Rongier M, Morin MC, Ndeïndoum U, Rambaud JC. Intestinal absorption of free oral hyperalimentation in the very short bowel syndrome. Gastroenterology. 1991;100(6):1502-1508. 
8. Amiot A, Messing B, Corcos O, Panis Y, Joly F. Determinants of home parenteral nutrition dependence and survival of 268 patients with non-malignant short bowel syndrome. Clin Nutr Edinb Scotl. 2013;32(3):368-374. doi:10.1016/j.clnu.2012.08.007.

9. Compher CW, Kinosian BP, Metz DC. Ghrelin does not predict adaptive hyperphagia in 301 patients with short bowel syndrome. JPEN J Parenter Enteral Nutr. 2009;33(4):428-

10. Molina A, Pita A, Farriol M, Virgili N, Soler J, Gómez JM. Serum leptin concentrations 432. doi: $10.1177 / 0148607108324583$.

11. Farriol M, Pita AM, Fernandez-Bustos MA, Delgado G. Dipeptidyl-peptidase IV in patients with short bowel syndrome. Clin Nutr Edinb Scotl. 2005;24(6):1099-1104.

12. Blundell JE, Caudwell P, Gibbons C, et al. Body composition and appetite: fat-free mass doi:10.1016/j.clnu.2005.07.001.

13. Lissner L, Habicht JP, Strupp BJ, Levitsky DA, Haas JD, Roe DA. Body composition and energy intake: do overweight women overeat and underreport? Am J Clin Nutr. $1989 ; 49(2): 320-325$. expenditure predict ad-libitum food and macronutrient intake in humans. Int J Obes 2005. 2014;38(2):243-251. doi:10.1038/ijo.2013.85. 
15. Senez C, Guys JM, Mancini J, Paz Paredes A, Lena G, Choux M. Weaning children from tube to oral feeding. Childs Nerv Syst ChNS Off J Int Soc Pediatr Neurosurg.

16. RStudio Team. RStudio: Integrated Development Environment for R. Boston, MA: RStudio, Inc.; 2016.

17. Royston JP. Algorithm AS 181: The W Test for Normality. J R Stat Soc Ser C Appl Stat. 1982;31(2):176-180. doi:10.2307/2347986.

18. Hopkins M, Finlayson G, Duarte C, et al. Modelling the associations between fat-free mass, resting metabolic rate and energy intake in the context of total energy balance. Int J Obes. 2016;40(2):312-318. doi:10.1038/ijo.2015.155.

19. Vainik U, Konstabel K, Lätt E, Mäestu J, Purge P, Jürimäe J. Diet misreporting can be

20. Cameron JD, Sigal RJ, Kenny GP, et al. Body composition and energy intake - skeletal muscle mass is the strongest predictor of food intake in obese adolescents: The HEARTY trial. Appl Physiol Nutr Metab Physiol Appl Nutr Metab. 2016;41(6):611-617. doi:10.1139/apnm-2015-0479.

21. Oppert JM, Dussault JH, Tremblay A, Després JP, Thériault G, Bouchard C. Thyroid hormones and thyrotropin variations during long term overfeeding in identical twins. $J$ Clin Endocrinol Metab. 1994;79(2):547-553. doi:10.1210/jcem.79.2.8045975. Diet in Patients With Severe Short Bowel Syndrome Living in the Southeastern United 
States. Nutr Burbank Los Angel Cty Calif. 2008;24(4):330-339.

342 doi:10.1016/j.nut.2007.12.016.

343 23. Murray CD, le Roux CW, Gouveia C, et al. The effect of different macronutrient

344 infusions on appetite, ghrelin and peptide YY in parenterally fed patients. Clin Nutr.

345 2006;25(4):626-633. doi:10.1016/j.clnu.2005.12.002.

346 24. Borer KT, Wuorinen E, Ku K, Burant C. Appetite Responds to Changes in Meal

347 Content, Whereas Ghrelin, Leptin, and Insulin Track Changes in Energy Availability. $J$

$348 \quad$ Clin Endocrinol Metab. 2009;94(7):2290-2298. doi:10.1210/jc.2008-2495.

349 25. Gil KM, Skeie B, Kvetan V, Askanazi J, Friedman MI. Parenteral Nutrition and Oral

350 Intake: Effect of Glucose and Fat Infusions. J Parenter Enter Nutr. 1991;15(4):426-432.

$351 \quad$ doi:10.1177/0148607191015004426.

352 26. Sriram K, Pinchcofsky G, Kaminski MV. Suppression of appetite by parenteral nutrition 353 in humans. J Am Coll Nutr. 1984;3(4):317-323.

354 27. Araújo ECF, Suen VMM, Marchini JS, Vannucchi H. Muscle mass gain observed in 355 patients with short bowel syndrome subjected to resistance training. Nutr Res.

$356 \quad$ 2008;28(2):78-82. doi:10.1016/j.nutres.2007.12.007. 